Vol. 40(2), pp. 24-32, Dec. 2021

ISSN 1821-536X (print)

ISSN 2619-8789 (electronic)
Tanzania Journal of Engineering and Technology

Copyright (C) 2021 College of Engineering and

Technology, University of Dar es Salaam

Review Paper

\title{
Review of Strategies for Curbing Traffic Congestion in Sub-Saharan Africa Cities: Technical and Policy Perspectives
}

\author{
Eradius Edward Rwakarehe \\ Department of Transportation and Geotechnical Engineering, College of Engineering and Technology \\ University of Dar es Salaam \\ *Corresponding author: eraddy2001@yahoo.co.uk, eradius@udsm.ac.tz
}

\begin{abstract}
This paper summarizes the causes of traffic congestion in sub-Saharan Africa (SSA) cities and the solutions to be adopted. According to the literature, the modal share for private cars, public transport (minibus and taxis); and walking \& cycling are 8\%, 34\% and $40 \%$ respectively. From these figures, it has been found that although the private car mode is still used relatively little (as compared to developed countries); contrary to the expectation, traffic congestion in SSA cities is worse compared to cities of developed countries. This implies that, traffic congestion problem in SSA cities is largely associated with limited availability of road infrastructure. As opposed to traffic congestion solutions to most of the cities in developed countries, road expansion is still one of the major solutions towards solving the same problem in SSA cities. However, the issue remains as to how many lane-kilometers should be added to reach the optimal level. It is clear that we cannot keep expanding roads without a limit; therefore, transportation experts and land-use planners need to establish the benchmarks that will serve as limiting indicators. Apart from relatively poor land-use planning and inadequacy of road infrastructure, it has also been found that disorganized and informal public transport is another major cause of traffic congestion in SSA cities.
\end{abstract}

Key words: Traffic Congestion, Public Transport, Car Ownership and Usage.

\section{INTRODUCTION}

Congestion is a significant problem in urban areas around the world. Increasing demand for travel will make the problem even more complex if appropriate solutions are not found and implemented. For developed countries, apart from other several strategies, efficient public transport is considered the major potential solution to the problem of urban road traffic congestion. However, this solution may not help much in solving the same problem in sub-Saharan Africa (SSA) cities. In SSA cities there are several problems before we reach to efficient public transport. According to International Association of Public Transport \& Africa Association of Public Transport (2010), Sietchiping et al. (2012), Njimanted and Mbohijim (2014), Dillip and Mmusho, (2016) Feikie et al. (2018) and Baba et al., (2020), traffic congestion is common problem to SSA cities, which is associated with other transport related problems. This is also confirmed by Mohamed and Heyden (2016) in their study on Urban Transport in SSA where they reviewed the status of transport services in the cities of Abidjan and Bouake 
(Ivory Coast), Abuja and Lagos (Nigeria), Accra and Kumasi (Ghana), Addis Ababa (Ethiopia), Dakar (Senegal), Dar es Salaam (Tanzania), Douala and Yaoundé (Cameroon), Kampala (Uganda), Kinshasa (Democratic Republic of Congo, Maputo (Mozambique), Nairobi (Kenya) and Ouagadougou (Burkina Faso).

Paris has the lower rate of car ownership than the rest of other cities in Europe. It has 0.5 cars per household while for other cities the situation is: 0.8 for London, 0.9 for Brussels and 1.1 for Madrid. The reason behind this low figure is considered to be the quality of public transport in Central Paris (Edwards and Smith, 2008). This study also found that the shortage of parking spaces encourages residents of Paris to use public transport or walk for short trips. Cars are mainly for trips to suburban shopping centres or during the weekend for moving out of the city. Unlike in New York and London, the Parisian authorities opted to invest in improving public transport instead of increasing parking charges to discourage the residents from driving.

On the other hand, it is suggested that improving public transport only is not enough to combat traffic congestion. The increase in car use, which is associated with increase in car ownership, may not be suppressed by improving public transit. It is car use that determines transit use, not transit use determines car use (Kitamura, 1989). The study also concluded that the increase in household car ownership increases car usage. It also found that, car use may be more effectively suppressed in the long-run by adopting policies to control car ownership instead of car use itself.

On the other hand, a study that presents the congestion fighting experience in Singapore found that it is car usage and not ownership that causes congestion. It is the better usage policy that can help to fight traffic congestion rather than ownership policy (Goh, 2002). However, it should be noted that in order to implement Singapore's approach, alternatives for those who cannot afford to pay for congestion price (which is the foundation for usage policy) should be in place. To some extent, this may limit applicability of this approach in SSA cities, which are characterized by inadequate and unattractive public transportation infrastructures and services; hence, lack of alternatives.

Therefore, it is clear that to combat traffic congestion problem, several mechanisms are needed. This can be achieved through combining different strategies that integrates engineering know-how, economics and public policies. However, the literatures cited above are all about cities in developed countries of which almost all conditions are totally different from those of developing countries. For instance, the measures proposed to fight traffic congestion in London can't directly be applied in Dar es Salaam, because the two cities are totally different in terms of transportation related factors especially city plan and the existing transport infrastructure. In order to tackle this problem, this paper discusses the causes of traffic congestion in SSA cities and the solutions to be adopted.

\section{METHODS AND MATERIALS}

\section{Definition of Traffic Congestion}

Traffic congestion is often understood but not formally defined. However, an engineering definition given by Highway Agencies can be summarized as the travel time or delay in excess of that normally incurred under light or free-flow travel condition (Grant-Muller and Laird, 2006). Traffic congestion is always characterized by slower speeds, longer trip times, and increased vehicular queuing or traffic jam. This situation occurs when a volume of traffic is close or equal to road capacity; and the situation is termed as saturation.

\section{Sources of Traffic Congestion}

Congestion results from the interaction of many different factors. According to Cambridge Systematics (2004), in general, 
root causes of congestion can be broken down into two main categories as follows:

Too much traffic for the available physical capacity to handle: A highway like other facilities has its maximum capacity; so, there is a limited number of vehicles that can be moved on a roadway for a given time at a desired safe speed. In transportation engineering, this is referred to as the physical capacity of the highway system. The physical capacity is determined by such things like number of lanes available to carry traffic, the curvature of the highway, side clearance, and interchange and intersection designs. Physical bottlenecks are locations where the physical capacity is restricted, with flows from upstream sections (with relatively higher capacities) being directed into them. Once traffic flow reaches stop-and-go conditions, the highway capacity is reduced, so fewer cars can get through the bottleneck because of the extra turbulence.

Traffic-influencing events: These include traffic incidents such as crashes and vehicle breakdowns, work zones, bad weather, special events and poorly timed traffic signals. Once these events occur, physical capacity of the roadway is reduced to a great extent. For instance, a closure of one lane reduces the road capacity by $68 \%$ on a 2-lane road, $47 \%$ on a 3-lane road, $44 \%$ on a 4-lane road and $25 \%$ on a 5+-lane road (Chin et al., 2004).

\section{Traffic Congestion Mitigation Measures}

There are several strategies/measures that can be used to curb traffic congestion. The biggest challenge is how to choose the appropriate one together with the procedure on how to implement it. The choice of a strategy depends on the prevailing circumstance(s) at that particular time. According to Chicago Area Transportation Study (1998), traffic congestion mitigation strategies can be summarised under the following twelve classes: transportation demand management measures, transportation systems management, measures to encourage high occupancy vehicle use, public transit capital improvements, public transit operational improvements, measures to encourage the use of non-motorized modes, congestion pricing, growth management, access management, incident management, intelligent transportation systems, capacity expansion. The detailed explanations for each strategy that includes description, general system benefits and impacts, policies and actions, application principles and analysis guidelines can be found on chapter three of the referred document. The problems with the choice(s) of these measures are discussed under the relevant Section of this paper.

\section{Passenger Transport Situation in Sub- Saharan Africa Cities}

This section gives the situation of passenger transport in SSA cities. Many of publicly owned and managed public transport companies in SSA ceased to exist in early 1990s as a result of structural adjustment policies that required SSA countries to comply with aid programmes associated with international agencies, in particular International Monetary Fund (IMF). Today throughout SSA, public transport to a large extent is dominated by the operations of disorganised informal sector. The dominance of these disorganized services hinders economic development and reduces the quality of life for citizens as the large number of vehicles required to meet demand causes not only congestion but also parking problems, pollution and low levels of road safety (International Association of Public Transport \& Africa Association of Public Transport, 2010). This is also supported by Njimanted and Mbohjim (2014) in their study about determinants of traffic congestion in the Metropolis of Douala, Cameroon; Dillip and Mmusho, (2016) in their study about evaluation of traffic congestion and Re-Engineering solutions for central areas of South African cities: A case study of Kimberley City; 
Feikie et al., (2018) on their study about perceptions of the factors causing traffic congestion and plausible measures to alleviate the challenge in Bloemfontein, South Africa; Baba et al., (2020) on the study about urban congestion and pollution: A quest for cogent solutions for Accra city and Mohamed and Heyden, (2016) on urban transport in SSA.

According to Figure 1, the modal share of informal collective transport (minibus and collective taxis) is $34 \%$ and non-motorized transport (walking and cycling) account for about $40 \%$ with walking being dominant. From these data, it is clear that up to now, people in SSA have mostly used walking and cycling to get around. The reason behind this is that other options, such as private cars, are not affordable for the majority of people. The modal share for private cars accounts for $12 \%$ on average. Furthermore, although the private car mode is still used relatively little (as compared to developed countries) due to low purchasing power of most of the people in SSA, contrary to the expectation, traffic congestion is worse in SSA cities compared to cities of developed countries. This implies that the transport problem in SSA is largely associated with limited availability of road infrastructures. As opposed to traffic congestion solutions in most of the cities in developed countries, road expansion is still one of the major solutions towards solving the same problems in SSA. However, this does not mean that other problems like poor land use planning, disorganised public transport and the like should not be tackled. Collective solution is inevitable. The issue here is: how many lane-kilometres should be added to reach the optimal level? It is clear that we cannot keep expanding the roads without a limit, otherwise the all land may become roads; which is not desirable. So far, there is no guideline on this matter. Therefore, it is imperative for transportation experts and land-use planners to establish the benchmarks such as 'lane-km per hectare per person'.

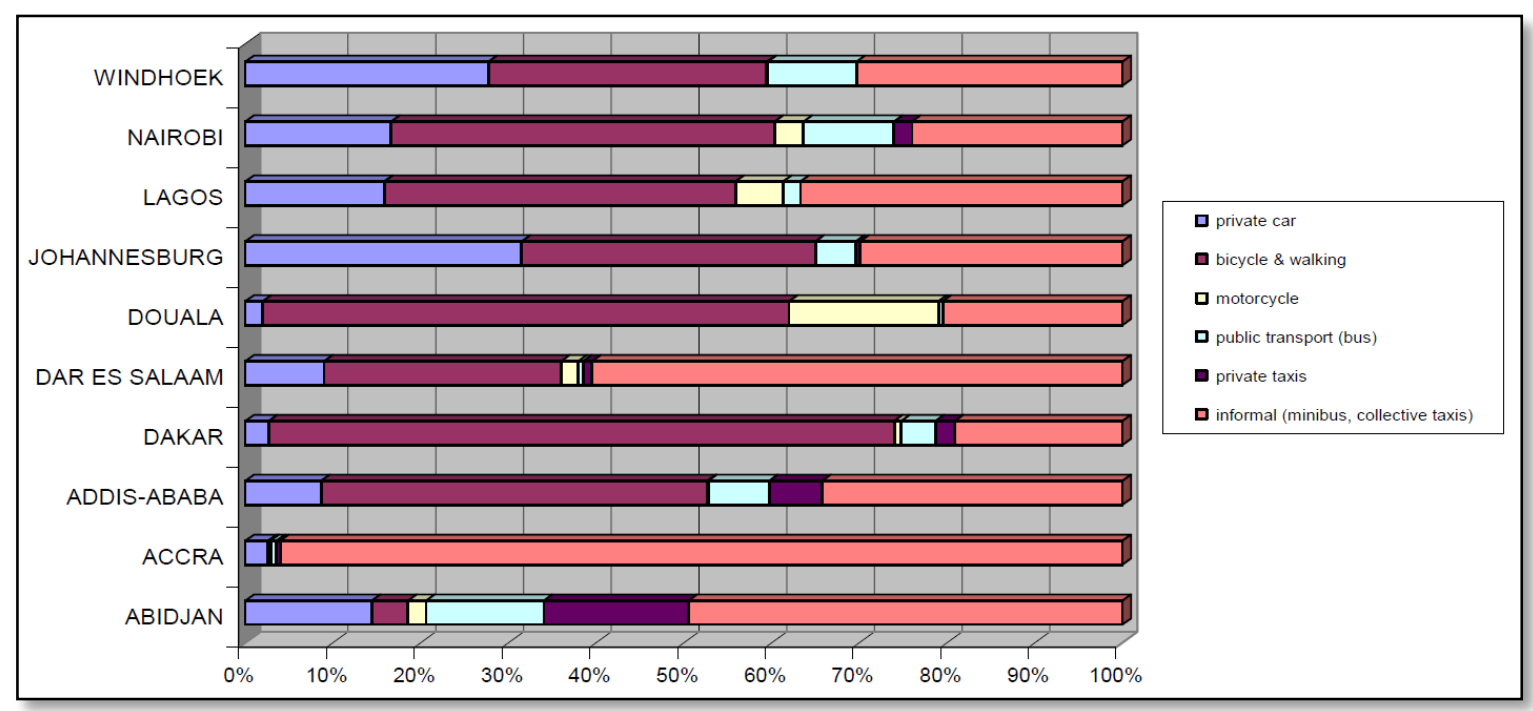

Figure 1: Transport modal share of selected SSA cities

Source: International Association of Public Transport \& Africa Association of Public Transport (2010)

\section{Singapore's Experience with Traffic Congestion Management}

Singapore is believed to be the best country in terms of traffic congestion management; therefore, it qualifies to be considered as the role model. Singapore is a small island city- state, of about 714 square kilometers in area, located at the crossroads of commercial and tourism at the southern tip of the Malaysian Peninsula. It has 5.69 million resident population, with a very high population density of 7,971 persons per square 
kilometer (compared to 34 in the United States). The climatic condition of the country is hot and humid, creating a heavy demand for air-conditioned private transportation. As of 2019, Singapore had 556,155 cars out of 967,768 registered motor vehicles traveling on 3,377 kilometers of roads, which is equivalent to a linear density of about 287 vehicles per kilometer. This is a very high figure compared to: 69 in Japan and 44 in the United States. Despite all of these comparative high figures, the traffic flow in Singapore is relatively good. The secret behind this situation is a better policy regulating transport industry in the country. This is in line with the study by Toh and Phang (1997).

It is better to note that Singapore did not arrive at that situation all of a sudden. There are so many ups-and-downs that it has passed through. Table 1 below summarizes the major measures that were introduced to curb road congestion in Singapore. From the Table together with the comparative statistical data in the paragraph above, it can be noted that an increase in the price of cars did not seriously discourage the purchase of Singaporeans. It is a nationwide system of automatic tolls that seriously discouraged their usage. Since it is car usage and not ownership that causes congestion, it can be concluded that 'Electronic Road Pricing' is the ultimate solution to Singapore's road congestion problem. Because of the system's flexibility, efficiency, non-intrusiveness and effectiveness, Singapore becomes the best country in the world in terms of traffic congestion management.

\section{Table 1: Major measures introduced to curb road congestion in Singapore}

\begin{tabular}{|c|c|c|c|}
\hline Year & Measure & Description of measures/systems & Success rate \\
\hline 1972 & $\begin{array}{l}\text { Additional } \\
\text { Registration } \\
\text { Fee (ARF) }\end{array}$ & $\begin{array}{l}\text { Extra levy imposed on new vehicle, } \\
\text { priced at } 5 \% \text { to } 140 \% \text { of the } \\
\text { vehicle's open market value } \\
\text { depending on the vehicle's capacity } \\
\text { and function. The aim was to } \\
\text { discourage people from buying new } \\
\text { cars. }\end{array}$ & $\begin{array}{l}\text { It initially tried to limit traffic } \\
\text { growth by making cars more } \\
\text { expensive to own but because of } \\
\text { good economic growth, still people } \\
\text { could manage to buy new cars. The } \\
\text { scheme was revised in } 1974 \text { and } \\
1975 \text {. }\end{array}$ \\
\hline 1975 & $\begin{array}{l}\text { Area Licensing } \\
\text { Scheme (ALS) }\end{array}$ & $\begin{array}{l}\text { Restrict access to CBD from } 7.30 \\
\text { a.m. to } 6.30 \text { p.m. on weekdays from } \\
7.30 \text { a.m. to } 2.00 \text { p.m. on Saturdays } \\
\text { through purchase of supplementary } \\
\text { licences. }\end{array}$ & $\begin{array}{l}\text { Initial drop in traffic into the CBD } \\
\text { was } 45 \% \text {. By } 1988 \text {, drop was not } \\
\text { sustained due to increase in } \\
\text { employment in the CBD. }\end{array}$ \\
\hline 1987 & $\begin{array}{l}\text { Mass Rapid } \\
\text { Transit (MRT) }\end{array}$ & $\begin{array}{l}\text { Serves heavy passenger transit } \\
\text { corridors. }\end{array}$ & $\begin{array}{l}\text { Ridership rose from } 346 \text { million in } \\
1998 \text { to } 360 \text { million in } 1999 \text {, an } \\
\text { increase of } 14 \text { million. }\end{array}$ \\
\hline 1990 & $\begin{array}{l}\text { Vehicle Quota } \\
\text { System (VQS) }\end{array}$ & $\begin{array}{l}\text { Certificate of Entitlement was } \\
\text { introduced, i.e., new car population } \\
\text { allowed to grow at } 3 \% \text { in tandem } \\
\text { with road capacity growth. } \\
\text { Motorists now need to bid for the } \\
\text { right to own a car. }\end{array}$ & $\begin{array}{l}\text { With VQS, 41,000 fewer vehicles } \\
\text { were registered between } 1990 \text { and } \\
1993 \text {. }\end{array}$ \\
\hline 1994 & $\begin{array}{l}\text { Off -Peak Car } \\
\text { (OPC) scheme }\end{array}$ & $\begin{array}{l}\text { Offer new and existing car owners } \\
\text { the option to save on car registration } \\
\text { and taxes in return for lower car } \\
\text { usage. }\end{array}$ & $\begin{array}{l}\text { Not very successful as most } \\
\text { motorists preferred ready use of car } \\
\text { for convenience. }\end{array}$ \\
\hline 1995 & $\begin{array}{l}\text { Road Pricing } \\
\text { Scheme (RPS) }\end{array}$ & $\begin{array}{lrr}\text { Manual road pricing } & \text { scheme } \\
\text { introduced for } & \text { linear } & \text { passage } \\
\text { vehicle flow, } & \text { i.e., } & \text { remove } \\
\text { bottlenecks } & \text { at } & \text { congested } \\
\end{array}$ & $\begin{array}{l}\text { Initial drop in traffic volume along } \\
\text { RPS monitored expressways } \\
\text { dropped by } 41 \% \text { from } 12,400 \text { to } \\
7,300 \text { vehicles while public }\end{array}$ \\
\hline
\end{tabular}




\begin{tabular}{|l|l|l|l|}
\hline & & $\begin{array}{l}\text { expressways or arterials outside } \\
\text { CBD. }\end{array}$ & $\begin{array}{l}\text { transportation travel speed } \\
\text { increased by 16\%. }\end{array}$ \\
\hline 1998 & $\begin{array}{l}\text { Electronic } \\
\text { Road Pricing } \\
(\text { ERP) }\end{array}$ & $\begin{array}{l}\text { Automated road pricing to reduce } \\
\text { the 147 enforcement personnel } \\
\text { needed for RPS and replace ALS, } \\
\text { OPC and RPS. }\end{array}$ & $\begin{array}{l}\text { Traffic volume on ERP monitored } \\
\text { roads dropped by 17\%. }\end{array}$ \\
\hline
\end{tabular}

Source: Toh and Phang (1997)

\section{Problems Associated with Choice and Evaluation of Congestion Mitigation Measures}

It is clear that in order to fight traffic congestion problem, several strategies have to be packaged together (Edwards and Smith, 2008; Kitamura, 1989). However, it is important to recognize that sometimes strategies can conflict one another as some may have conflicting objectives while others may be competing for the same market. Determining the potential benefits arising from a combination of these strategies becomes a problem especially at economic evaluation stage. To resolve this problem, studies recommends two approaches. First approach, if the first strategy reduces peak trips by $5 \%$ for instance, the impacts of the second strategy would be evaluated based on the remaining $95 \%$ of the trips, not the original $100 \%$. Second, to consider one strategy as primary and the other one as secondary. The estimated benefits of the primary strategy can then be enhanced or reduced by a marginal factor to reflect the countervailing effects of the secondary strategies (Chicago Area Transportation Study, 1998).

The choice of traffic congestion mitigation strategy is another challenging issue. Several factors have to be considered so as to choose the best strategy to be adopted. For instance, for short term measures and treatment of bottlenecks, capacity expansion is considered to be the best option (European Conference of Ministers of Transport, 2007; Litman, 2011). However, this option cannot provide a longterm solution due to the effects of generated traffic. Traffic congestion tends to maintain equilibrium. If road capacity increases, the number of peak-period trips also increases until congestion again limits further traffic growth (Litman, 2011). This is also supported by a study by Noland (2001), which found that $10 \%$ increase in capacity leads to a 3-6\% increase in traffic volume in the short-run and to $7-10 \%$ increase in traffic volume in the long-run.

According to the literatures above, capacity expansion is discouraged when considering long-term traffic congestion mitigation strategies. However, one has to be careful especially when dealing with the situation in SSA which is characterized by poor and inadequate transportation infrastructure. It is unfortunate that most of cities in SSA tend to adopt solutions from developed countries without noting that solutions designed for developed countries' cities can not be directly applied to their cities. The causes of traffic congestion in developed countries are definitely different from that of SSA. For instance, while car ownership per household in London was 0.8 (Edwards and Smith, 2008), in Dar es Salaam the rate was 0.1 (JICA, 2008); and yet the congestion problem was worse in Dar es Salaam compared to London. Other things being equal, one would expect a city with higher car ownership rate to face a relatively severe traffic congestion problem. The opposite is true when comparing cities in SSA with other cities in developing countries. This was also confirmed by International Association of Public Transport \& Africa Association of Public Transport (2010). Analysis from the findings of these three literatures above concludes that apart from relatively poor urban planning; inadequacy of road infrastructure is currently the major cause of traffic congestion in SSA cities. 
Therefore, a proper guidance is needed as to what level capacity expansion becomes no longer a viable long-term option. It is unfortunate that so far, no any literature gives such guidance. As already noted earlier, it is imperative for transportation experts and land-use planners to establish the benchmarks such as 'lane-km per hectare per person'. This will clear the confusion that seems to exist in SSA by adopting the idea that capacity expansion has never been a solution to traffic congestion as suggested by Litman (2011) while the current major cause of the problem in SSA cities is the lack of adequate capacity. While taking initiatives to curb traffic congestion, history of transportation industry in developed counties should be well utilized by taking an advantage of learning from the mistakes already made in those countries so that the same should not repeat.

Availability of fund is another issue dictating the choice of congestion mitigation strategy. The problem is more common in SSA cities that are characterized by inadequate public transport infrastructure financing capacity (Briceño-Garmendia et al., 2004). This complicates the matter to the extent that sometimes an option that gives high net benefit may not be adopted because of lack of enough funds to implement it. Optimization skills are highly needed in such situations. It is an author's hypothesis that developing countries, sometimes are quickly buying Litman's idea of not opting capacity expansion as the starting point towards solving traffic congestion problems in their cities because of financial problems. Capacity expansion is ranked the most expensive among the currently suggested options for combating traffic congestion problem.

\section{CONCLUSIONS AND \\ RECOMMENDATIONS \\ Conclusions}

This paper discusses the causes of traffic congestion in SSA cities and the solutions to be adopted both technical and policy related. According to the literature, it has been found that the modal share for private cars, public transport (minibus and taxis); and walking \& cycling in SSA cities are about $12 \%, 34 \%$ and $40 \%$ on average respectively. From these figures, it can be seen that although private cars are still used relatively little (as compared to cities in developed countries) due to low purchasing power of most of the people in SSA, contrary to the expectation, traffic congestion is worse in SSA cities compared to the cities in developed countries. This implies that traffic congestion problem in SSA cities is largely associated with limited availability of road infrastructures. As opposed to traffic congestion solutions to most of the cities in developed countries, road expansion is still one of the major solutions towards solving the same problem in SSA.

Apart from relatively poor urban planning, disorganized and informal public transport is also one of the major causes of traffic congestion in SSA cities as large number of vehicles is required to meet the demand. It has also been shown that most of the traffic congestion solutions applicable to cities of developed countries may not directly be implemented in SSA cities, because of heterogeneities in several aspects. Even the causes of congestion in developed countries are different from that of SSA cities. It was also found that the choice of congestion mitigation strategies in SSA cities, in most cases depend on the available fund instead of formal engineering and economic evaluation techniques.

\section{Recommendations}

In order to curb traffic congestion problem in SSA cities, the following should be done:

- Capacity should be added to the existing road infrastructure up to a reasonable level. However, the term 'reasonable level' is likely to subjective. A study should be done to establish benchmarks like 'lane-km per hectare 
per person' that will be taken as a limiting indicator.

- The work for road infrastructure expansion should go parallel with improvement of public transport services. With the low-income problem existing in SSA as compared to let say London or Paris, etc., people might be forced to have private cars not because of luxury but due to the lack of adequate and attractive public transport. Improvement in this sector is likely to deter the rate of increase in car ownership that does not match with income of the people in SSA.

- By tracing back, the history of transportation industry in developed countries, it is clear that no matter how many lane-kilometres are added, as long as economic is growing, congestion will still build-up. To fight that, Singapore's car usage policy is still the best option. However, that should be applied after establishing proper public transport system that will serve as an alternative to private car ownership and/or use. With the current situation, restricting people in SSA to own private cars is an insult to them.

Finally, in carrying out all of these improvements, history of transportation industry in cities of developed counties should be well utilized by taking an advantage of learning from the mistakes already made in those countries so that the same should not repeat. Moreover, it should be noted that any traffic congestion solution adopted from cities of developed countries should incorporate issues of heterogeneities.

\section{REFERENCES}

Baba, I. M., Peng, L., and Xu, Y (2020). Urban Congestion and Pollution: A Quest for Cogent Solutions for Accra City. IOP Conference Series: Earth and Environmental Science 435 (2020) 012026.
Briceño-Garmendia, C., Estache, A. and Shafik, N. (2004). Infrastructure Services in Developing Countries: Access, Quality, Costs and Policy Reform, World Bank Policy Research Working Paper 3468, Washington, D.C.

Cambridge Systematics (2004). Traffic Congestion and Reliability: Linking Solutions to Problems. Cambridge, Massachusetts, USA.

Chicago Area Transportation Study (1998). Congestion Mitigation Handbook, Chicago, Illinois.

Chin, S. M., Franzese, O., Greene, D. L., Hwang, H. L. and Gibson, R. C. (2004). Temporary Losses of Highway Capacity and Impacts on Performance: Phase 2. Oak Ridge National Laboratory \& The University of Tennessee, Oak Ridge, Tennessee, USA.

Dillip, K. D. and Mmusho, K. (2016). Evaluation of Traffic Congestion and Re-Engineering Solutions for Central Areas of South African Cities: A Case Study of Kimberley City. International Conference on Traffic and Transport Engineering, Belgrade, November 24 25, 2016: 524 - 532.

Edwards, T. and Smith S. (2008). Transport Problems Facing Large Cities, NSW Parliamentary Library Research Service, New South Wales.

European Conference of Ministers of Transport (2007). Managing Urban Traffic Congestion, OECD, Paris, France.

Feikie, X. E., Das. D. K. and Mostafa, M. M. H. (2018). Perceptions of the Factors Causing Traffic Congestion and Plausible Measures to Alleviate the Challenge in Bloemfontein, South Africa. $37^{\text {th }}$ Annual Southern African Transport Conference 9 - 12 July 2018, Pretoria, South Africa.

Grant-Muller, S. and Laird, J. (2006). Costs of Congestion: Literature Based Review of Methodologies and Analytical Approaches, ITS, University of Leeds.

Goh, M. (2002). Congestion Management and Electronic Road Pricing in 
Singapore, Journal of Transport Geography, 10: 29-38.

Kitamura, R. (1989). A Causal Analysis of Car Ownership and Transit Use, Department of Civil Engineering, University of California, Davis, USA.

International Association of Public Transport \& Africa Association of Public Transport (2010). Report on Statistical Indicators of Public Transport Performance in Africa. Available at: http://www.uitp.org/knowledge/pdf/Rep ort_on_statistical_indicators_of_publict ransportperformanceinS-SA.pdf.

JICA (2008). Dar es Salaam Transport Policy and System Development Master Plan. Dar es Salaam, Tanzania.

Litman, T. (2011). Generated Traffic and Induced Travel: Implications for Transport Planning, Victoria Transport Policy Institute (www.vtpi.org).

Mohamed, H. and Heyden, C. V. D. (2016). Urban Transport in Sub- Saharan Africa. Infrastructure Consortium for Africa, Côte d'Ivoire.
Njimanted, G. F. and Mbohjim O. M. (2014). Determinants of Traffic Congestion in the Metropolis of Douala, Cameroon: An Integrated Approach. Journal of the Cameroon Academy of Sciences, 11(2 \& 3): $209-221$.

Noland, R. (2001). Relationships Between Highway Capacity and Induced Vehicle Travel, Paper Presented to the 78th Annual Meeting of the Transportation Research Board, Washington, D.C.

Sietchiping, R., Permezel, M. J. and Ngomsi, C. (2012). Transport and mobility in sub-Saharan African cities: An overview of practices, lessons and options for improvements. International Journal of Urban Policy and Planning, 29: 183 - 189.

Toh, R. S. and Phang, S. (1997). Curbing Urban Traffic Congestion in Singapore: A Comprehensive Review. The Logistics and Transportation Review, $37(2)$. 